\title{
Alfuzosin Hydrochloride Transdermal Films: Evaluation of Physicochemical, In Vitro Human Cadaver Skin Permeation and Thermodynamic Parameters
}

\author{
Satyanarayan Pattnaik, Kalpana Swain, Parthagan Choudhury, Pradeepta K. Acharya, Subrata \\ Mallick
}

College of Pharmaceutical Sciences (SP, KS, PC, PKA), Mohuda, Berhampur, Orissa, India and School of Pharmaceutical Sciences (SM), SOA University, Ghatikia, Bhubaneswar, Orissa, India

\begin{abstract}
Purpose: The main objective of the investigation was to develop a transdermal therapeutic system for alfuzosin hydrochloride and to study the effects of polymeric system and loading dose on the in vitro skin permeation pattern.

Materials and Methods: Principles of experimental design have been exploited to develop the dosage form. Ratio of ethyl cellulose (EC) and polyvinyl pyrrolidone (PVP) and loading dose were selected as independent variables and their influence on the cumulative amount of alfuzosin hydrochloride permeated per $\mathrm{cm}^{2}$ of human cadaver skin at $24 \mathrm{~h}\left(\mathrm{Q}_{24}\right)$, permeation flux $(\mathrm{J})$ and steady state permeability coefficient $\left(\mathrm{P}_{\mathrm{SS}}\right)$ were studied using experimental design. Various physicochemical parameters of the transdermal films were also evaluated. Activation energy for in vitro transdermal permeation has been estimated.

Results: Ratio of EC and PVP was found to be the main influential factor for all the dependent variables studied. Drug loading dose was also found to influence the dependent variables but to a lesser extent. Physicochemical parameters of the prepared films were evaluated and found satisfactory. Activation energy for alfuzosin permeation has also been estimated and reported.

Conclusion: The therapeutic system was found to be dermatologically non-irritant and hence, a therapeutically effective amount of alfuzosin hydrochloride can be delivered via a transdermal route.
\end{abstract}

Key words: alfuzosin hydrochloride; administration, cutaneous; polymers

Int Braz J Urol. 2009; 35: 716-29

\section{INTRODUCTION}

Benign prostatic hypertrophy $(\mathrm{BPH})$ is a condition characterized by a nodular enlargement of prostatic tissue leading to obstruction of the urethra. In a large community-based survey, lower urinary tract symptoms (LUTS) secondary to BPH were reported in $25 \%$ of men aged $>50$ years (1). LUTS including increased urinary frequency, nocturia, incomplete emptying, and urinary hesitancy are often associated with BPH. These symptoms can be caused by altered function of the smooth muscle tone that is regulated by the alpha- 1 adrenergic receptors in the prostate and its capsule, the bladder base and neck, and the prostatic urethra (2). It is thought that alpha-1 adrenergic receptor antagonists may be implicated in the pathophysiology of BPH and may cause relaxation of smooth muscles, improvement in urine flow and 
reduction in LUTS (3). Consequently, American Health Care Policy and Research (AHCPR) guidance recommended alpha-blockers as a first-line therapy for $\mathrm{BPH}$. Alfuzosin, a quinazoline derivative, is a selective and competitive alpha-1 adrenoceptor antagonist. It distributes preferentially in the prostate, compared with plasma, and decreases the sympathetically controlled tone of prostatic smooth muscle. As a result, lower urinary tract symptoms suggestive of benign prostatic hyperplasia (BPH) are improved (4).

Alfuzosin hydrochloride is available in three formulations: an immediate release standard form, typically $2.5 \mathrm{mg}$ three times per day, a $5-\mathrm{mg}$ sustained-release form given twice per day, and a 10 $\mathrm{mg}$ once daily sustained-release form $(4,5)$. The absolute bioavailability of alfuzosin is about $49 \%$ under fed conditions, while the corresponding value under fasting conditions is approximately $25 \%$ (6). This shows that food has a significant impact on the oral absorption of alfuzosin. This originates the need for an alternative route of administration, which can bypass the hepatic first-pass metabolism. Transdermal route is an alternative choice of route of administration for such drugs. Various physicochemical parameters like molecular weight, $\log \mathrm{P}$ value and aqueous solubility of alfuzosin hydrochloride are $425.92,1.51$ at a $\mathrm{pH}$ of 7.4 and $>10 \%$ respectively. These favorable parameters make it an ideal drug candidate for transdermal delivery. Transdermal films offer added advantages such as maintenance of constant and prolonged drug level, reduced frequency of dosing, minimization of inter- and intrapatient variability, self administration, and easy termination of medication, leading to patient compliance (7).

The transdermal permeation can be treated as a diffusion process through a selectively permeable membrane. The concentration of the applied solute species at the surface layers is not usually equal to but related to its concentration in the applied vehicle in accordance with the vehicle/stratum corneum sorption isotherm. The linear isotherm can be defined in terms of the distribution coefficient between the vehicle and the stratum corneum. It is considered that the transdermal flux is directly proportional to the concentration difference across the skin barrier (8). Drug permeation through the skin following transdermal delivery is also influenced by various design factors such as polymer species, internal structure of the polymer matrix and drug-loading dose. The effects of the above-mentioned factors must be elucidated in detail in order to develop an optimum delivery system, first in vitro and then in vivo. In the present study, we have assessed the effects of polymeric concentration, its blend and drug-loading dose on the in vitro permeation pattern of alfuzosin hydrochloride from its transdermal films.

\section{MATERIALS AND METHODS}

\section{Materials}

Alfuzosin hydrochloride was obtained as a gift sample from Cipla Ltd. (Mumbai, India). Ethyl Cellulose (EC; ethoxy content $47.5-49 \%$, viscosity $14 \mathrm{cps}$ in $5 \% \mathrm{w} / \mathrm{w}$ solution in 80:20 toluene/ethanol at $25^{\circ} \mathrm{C}$ ) was purchased from BDH Chemicals Ltd., (Poole, England). Polyvinylpyrrolidone (PVP; K value: 26-35) and Polyvinylalcohol (PVA) were purchased from HiMedia Laboratories Pvt. Ltd., (Mumbai, India) and S.D. Fine-Chem. Ltd. (Boisar, India), respectively. Di-n- Butylphthalate was purchased from Central Drug House (P) Ltd., (Mumbai, India).

\section{Statistical Experimental Design}

A $3^{2}$ full factorial design was used in development of dosage form and two factors were evaluated, each at three levels. In the present investigation, ratio of EC and PVP $\left(\mathrm{X}_{1}\right)$ and drug loading dose $\left(\mathrm{X}_{2}\right)$ were selected as independent variables. The cumulative amount of alfuzosin hydrochloride permeated per $\mathrm{cm}^{2}$ of human cadaver skin at $24 \mathrm{~h}\left(\mathrm{Q}_{24}\right)$, permeation flux $(\mathrm{J})$ and steady state permeability coefficient $\left(\mathrm{P}_{\mathrm{SS}}\right)$ were chosen as dependent variables. Ratio of EC and PVP was evaluated at 30:70(-1), 20:80(0) and 10:90(+1), while alfuzosin loading dose was evaluated at $30 \%$ $(-1), 40 \%(0)$, and $50 \%(+1)$ of total polymer weight. Design-Expert software (Version. 7.1.3, Stat-Ease Inc., Minneapolis, USA) was used for the generation and evaluation of the statistical experimental design. 


\section{Alfuzosin Transdermal Films}

\section{Preparation of Transdermal Films}

Experimental transdermal films were prepared at all possible combinations (Table-1). Films composed of different ratios of EC and PVP containing alfuzosin hydrochloride $(\sim 1.05 \mathrm{mg} / \mathrm{square}$ centimeter film) were prepared by solvent evaporation technique. Di-n-butylphthalate was incorporated as a plasticizer at a concentration of $30 \% \mathrm{w} / \mathrm{w}$ of dry weight of polymers. Alfuzosin hydrochloride was dissolved in chloroform followed by addition of polymers and plasticizer with constant stirring. The matrix was prepared by pouring the homogeneous dispersed solution on 4\% PVA backing membrane in a flat bottomed petridish, covered with perforated aluminum foil, and dried at $40^{\circ} \mathrm{C}$ for $24 \mathrm{~h}$. The dry films with drug dissolved in the matrix were removed and kept in desiccators until use.

\section{Evaluation of Physicochemical Parameters}

\section{Content Uniformity}

Drug content uniformity was determined by dissolving each film in chloroform and filtering with Whatman filter paper $(0.45 \mu \mathrm{m})$. The filtrate was evaporated and drug residue dissolved in normal saline. The drug content was analyzed at $242 \mathrm{~nm}$ using a UV spectrophotometer (Shimadzu, Japan). The experiments were performed in triplicate, and average values were reported.

\section{Moisture Uptake}

Accurately weighed films kept in a desiccator at normal room temperature for $24 \mathrm{~h}$ were taken out and placed in desiccators containing $100 \mathrm{~mL}$ of super saturated solution of potassium chloride to maintain $84 \%$ relative humidity until a constant weight for the films were obtained. The percentage of moisture uptake was calculated as the difference between final and initial weight with respect to initial weight (9). The percentage moisture absorption at laboratory ambient condition $\left(30^{\circ} \mathrm{C}\right.$ and $\left.64 \% \mathrm{RH}\right)$ was also calculated.

\section{Moisture Content}

The prepared films were weighed individually and kept in a desiccator containing activated silica at room temperature until it showed a constant weight. The percentage of moisture content was calculated as a difference between initial and final weight with respect to final weight (9).

\section{Flatness}

Longitudinal strips were cut out from the prepared films. The length of each strip was measured, and than variation in the length due to the non-uniformity in flatness was measured. Flatness was calculated by measuring constriction of strips, and a $0 \%$ constriction was considered to be $100 \%$ flatness (9).

\section{Folding Endurance}

This was determined by repeatedly folding the film at the same place until it broke. The number of times the film could be folded at the same place without breaking gave the value of folding endurance.

\section{Fourier Transform Infrared (FT - IR) Study}

The active pharmaceutical ingredient, alfuzosin $\mathrm{HCl}$ and mixture of it with the polymers (PVP, EC) were mixed separately with IR grade $\mathrm{KBr}$ in the ratio of 100:1 and corresponding pellets were prepared by applying pressure in a hydraulic press. The pellets were scanned over a wave number range of 4000-400 $\mathrm{cm}^{-1}$ in Fourier transform infrared spectrophotometer (Perkin Elmer, Switzerland).

\section{Scanning Electron Microscopy (SEM)}

The surface morphology of the film was recorded with a Jeol Scanning Electron Microscope (Model: JSM 5200, Japan). The samples were 
Alfuzosin Transdermal Films

Table 1 - Composition and observed responses from randomized runs in $3^{2}$ full factorial design.

\begin{tabular}{|c|c|c|c|c|c|}
\hline \multirow[t]{2}{*}{ Run } & \multicolumn{2}{|c|}{ Factors } & \multicolumn{3}{|c|}{ Observed Responses ${ }^{\mathrm{C}}$} \\
\hline & $\begin{array}{c}\mathbf{X}_{1}^{\mathrm{a}} \\
\text { (EC: PVP) }\end{array}$ & $\begin{array}{c}\mathbf{X}_{2}^{\mathbf{b}} \\
\text { (Drug loading) }\end{array}$ & $\begin{array}{c}\mathbf{Q}_{24} \\
\left(\mu \mathrm{g} / \mathrm{cm}^{2}\right)\end{array}$ & $\begin{array}{c}\mathbf{J} \\
\left(\mu \mathrm{g} / \mathrm{cm}^{2} . h\right)\end{array}$ & $\begin{array}{c}\mathbf{P}_{\mathrm{ss}}\left(\times 10^{-3}\right) \\
(\mathrm{cm} / \mathrm{h})\end{array}$ \\
\hline 1 & -1 & -1 & $106.91(1.43)$ & $5.125(0.13)$ & 6.488 \\
\hline 2 & -1 & 0 & $123.54(0.86)$ & $5.804(0.09)$ & 5.527 \\
\hline 3 & -1 & +1 & $131.16(1.73)$ & $6.091(0.22)$ & 4.632 \\
\hline 4 & 0 & -1 & $142.77(1.22)$ & $6.609(0.16)$ & 8.366 \\
\hline 5 & 0 & 0 & $145.62(1.51)$ & $6.80(0.21)$ & 6.481 \\
\hline 6 & 0 & +1 & $151.05(1.96)$ & $7.021(0.08)$ & 5.339 \\
\hline 7 & +1 & -1 & $154.07(1.77)$ & $7.056(0.14)$ & 8.932 \\
\hline 8 & +1 & 0 & $160.11(0.97)$ & $7.346(0.07)$ & 6.996 \\
\hline 9 & +1 & +1 & $167.21(2.05)$ & $7.627(0.19)$ & 5.800 \\
\hline
\end{tabular}

${ }^{a}$ Levels of ratio of EC: $P V P\left(X_{1}\right)$ as 30:70(-1), 20:80(0) and 10:90(+1). ${ }^{b}$ Levels of drug loading $\left(X_{2}\right)$ as $30 \%(-1), 40 \%(0)$ and $50 \%$ $(+1) .{ }^{c}$ Data shown are mean of three determinations and figure in the parentheses indicates standard deviation.

mounted on an aluminum stab by using a double-sided adhesive tape. Then it was placed in an ion coater unit (Model: IB-2, Hitachi, Tokyo, Japan) for gold coating (200 A). During gold coating process the samples were exposed to vacuum of $10^{-50} \mathrm{~mm}$. Afterwards, an accelerating voltage of $25 \mathrm{kV}$ was applied and the image was photographed by Asia Pentex Camera of $35 \mathrm{~mm}$ film.

\section{In-vitro Drug Permeation Studies}

The extent and rate of skin permeation of alfuzosin hydrochloride through the human cadaver skin were carried out using Keshary-Chein diffusion cell. The receptor compartment was filled with $20 \mathrm{~mL}$ normal saline $(0.9 \% \mathrm{w} / \mathrm{v}$ of $\mathrm{NaCl})$ and its temperature was maintained at $32 \pm 5^{\circ} \mathrm{C}$ during the experiment. Exceptionally, during estimation of activation energy for permeability, the permeation study was conducted at various temperatures, i.e. $32^{\circ} \mathrm{C}, 40^{\circ} \mathrm{C}$ and $45^{\circ} \mathrm{C}$. Owing to higher aqueous solubility of alfuzosin $\mathrm{HCl}$, normal saline has been chosen as the receptor fluid. The diffusional area (cross section area) of the diffusion cell was $1.766 \mathrm{~cm}^{2}$. The receptor fluid is constantly agitated at $100 \mathrm{rpm}$ by a Teflon coated magnetic bead. The film (about $1.8 \mathrm{~cm}^{2}$ ) was applied under occlusion (using Leucoplast ${ }^{\circledR}$ tape) on the epidermal surface of the human cadaver skin fitted between the donor and receptor compartments of the diffusion cell. The whole of the receptor fluid was collected from the sampling port at predetermined time interval and replaced immediately with fresh normal saline. A similar set was run simultaneously using the film (without drug) at the donor compartment as a skin film control system to avoid the influence of inherent extracts from the skin or leaching of any material from the film without drug on the absorbance at $242 \mathrm{~nm}$, at which the sample aliquots were analyzed spectrophotometrically. The amount of drug permeated per square $\mathrm{cm}$ at each time interval was estimated and subjected to further data analysis.

\section{Permeation Data Analysis and Statistics}

The flux $\left(\mu \mathrm{g} / \mathrm{cm}^{2}\right.$.h) of alfuzosin hydrochloride was calculated from the slope of the plot of the 
cumulative amount of alfuzosin hydrochloride permeated per $\mathrm{cm}^{2}$ of human cadaver skin at steady state against the time using linear regression analysis. The steady state permeability coefficient $\left(\mathrm{P}_{\mathrm{SS}}\right)$ of the drug through human cadaver skin was calculated by using the following equation:

$$
\mathrm{P}_{\mathrm{SS}}=\mathrm{J} / \mathrm{C}
$$

Where, $\mathrm{J}$ is the flux and $\mathrm{C}$ is the initial concentration of alfuzosin hydrochloride in the film. The observed difference in the permeation parameters of alfuzosin hydrochloride in different formulations were compared by using one way analysis of variance (ANOVA) followed by all pair wise multiple comparison procedure such as Holm-Sidak test at overall significance level of 0.05 using SigmaStat software (SigmaStat 3.5, SPSS Inc, Chicago, IL, USA). The permeation data was subjected to Peppas kinetic model fitting. A simple, semi-empirical equation based on the Peppas model can be used to analyze data of controlled release of drugs from polymer matrices.

$$
\mathrm{M}_{\mathrm{t}} / \mathrm{M}_{\infty}=\mathrm{kt} \mathrm{t}^{\mathrm{n}}
$$

Where, $M_{t} / M_{\infty}$ is the fraction of drug released up to time $\mathrm{t}, \mathrm{k}$ is a constant comprising the structural and geometric characteristics of the matrix, and n, the diffusion exponent, is a parameter that depends on and is used to characterize the release mechanism. For the case of cylindrical matrix, in particular, $\mathrm{n}=$ 0.45 corresponds to a Fickian diffusion release (case I diffusional), $0.45<\mathrm{n}<0.89$ to an anomalous (nonFickian) transport, $\mathrm{n}=0.89$ to a zero-order (case II) release kinetics, and $n>0.89$ to a super Case II transport (10).

\section{Estimation of Thermodynamic Parameter}

Activation energy for permeation provides insight into mechanisms of transmembrane mobility of drug molecules $(11,12)$. Activation energy for permeability of alfuzosin hydrochloride from its transdermal system (run 9) across human cadaver skin was estimated by measuring the permeability of drug at various temperatures like $32^{\circ} \mathrm{C}, 40^{\circ} \mathrm{C}$ and $45^{\circ} \mathrm{C}$ using the Arrhenius equation:

$$
\mathrm{k}=\mathrm{Ae}^{-\mathrm{Ea} / \mathrm{RT}}
$$

where $\mathrm{k}$ is the specific reaction rate, $\mathrm{A}$ is a constant commonly referred to as the frequency factor, $\mathrm{R}$ is the gas constant, and $\mathrm{T}$ is temperature. The slope of the plot of $\log \mathrm{P}_{\mathrm{SS}}$ versus $1 / \mathrm{T}$ can be related to $\mathrm{E}_{\mathrm{a}}$ as follows:

$$
\text { Slope }=-E_{a} / 2.303 R
$$

\section{Primary Skin Irritation Studies}

Albino rabbits each weighing 1.5 to $2.0 \mathrm{~kg}$ and 24 months of age were used in this study ( $\mathrm{n}=$ 6 ). The animals were singly housed in suspended stainless steel caging with mesh floors in the animal unit under controlled temperature $\left(27 \pm 2^{\circ} \mathrm{C}\right)$ and 12 hours light/dark cycle. They were fed a standard laboratory diet and filtered tap water was provided ad libitum. Following acclimation to the laboratory, a group of animals was prepared by clipping the dorsal surface of each rabbit's trunk free of hair. The skin was cleared with rectified spirit and the transdermal film was secured using surgical adhesive tape. Elizabethan collars were placed on each rabbit and they were returned to their designated cages. After 24 hours of exposure, the films were removed and the animals were examined for any sign of erythema or edema. The individual dose sites were scored according to the Draize scoring system (13) at approximately 1, 24, 48 and 72 hours after film removal. The primary dermal irritation index (PDII) was calculated by adding the average erythema and edema scores for the 1, 24, 48 and 72 hours scoring intervals and dividing by the number of evaluation intervals i.e. 4. The test sample is considered non irritating, if PDII is $<0.5$; slightly irritating, if PDII is $0.5-2.0$; moderately irritating, if PDII is 2.1 5.0 and severely irritating, if PDII is $>5.0$. Ethical approval for the handling of experimental animals was obtained from the Institutional Animal Ethical Committee (IAEC) formed for this purpose. 


\section{Stability Studies}

A short term stability testing of run 9 was conducted for three months at laboratory ambient conditions $\left(25^{\circ} \mathrm{C}, 60 \% \mathrm{RH}\right)$. On completion of the third month, films were retrieved to assay their drug content and physical appearance.

\section{RESULTS AND DISCUSSION}

\section{Evaluation of Physicochemical Parameters}

A summary of the results of physicochemical studies is presented in Table-2. The drug content in the prepared films was found to be more than $99 \%$ and a low standard deviation indicates uniformity in drug content. The result of the moisture uptake (\%) and moisture content (\%) studies revealed that the moisture uptake/content was found to increase with increasing concentration of hydrophilic polymer PVP. The moisture uptake was increased at higher humidity conditions as compared to at ambient conditions. The low moisture uptake at laboratory ambient condition
$(3.89 \pm 0.91$ to $5.33 \pm 0.89 \%)$ protects the material from microbial contamination and bulkiness of the films. Again small moisture content $(3.13 \pm 1.52$ to $5.08 \pm 1.08 \%$ ) in the formulations helps the material to remain stable and from becoming a completely dried and brittle film (14). The results of flatness study showed that none of the formulation had the difference in the strip lengths before and after their cuts, thus indicating $100 \%$ flatness. It indicates $0 \%$ constriction in the films and thus they could maintain a smooth surface when applied onto the skin leading to intimate contact and hence better drug permeation. Folding endurance study assured about its flexibility.

\section{FT - IR Study}

The IR spectra of alfuzosin hydrochloride and physical mixture of drug and polymers showed all characteristic bands of alfuzosin hydrochloride. In case of IR spectra of matrix film (run 9) containing drug and polymers, changes in the area of C-O-C skeletal vibration in 1200 to $1000 \mathrm{~cm}^{-1}$ range (Figure-1) of glucose unit in cellulosed polymer appeared, showing differences of glucose bond orientation solid disper-

Table 2 - Physicochemical properties of transdermal films.

\begin{tabular}{lcccccc}
\hline Runs & $\begin{array}{c}\text { Drug Content } \\
(\%)\end{array}$ & \multicolumn{2}{c}{ Moisture Uptake $^{\mathrm{a}}(\%)$} & $\begin{array}{c}\text { Moisture Content } \\
(\%)\end{array}$ & $\begin{array}{c}\text { Flatness }^{\mathrm{a}} \\
(\%)\end{array}$ & Folding Endurance $^{\mathrm{a}}$ \\
\hline 1 & $\mathbf{R H ~ 6 4 \%}$ & $\mathbf{R H ~ 8 4 \%}$ & $3.13(1.52)$ & 100 & $38.66(0.57)$ \\
2 & $99.36(0.23)$ & $3.92(0.93)$ & $4.61(1.07)$ & $3.82(0.44)$ & 100 & $37.66(0.57)$ \\
3 & $99.52(0.44)$ & $3.89(0.91)$ & $4.75(1.08)$ & $3.21(1.27)$ & 100 & $36.33(1.15)$ \\
4 & $99.67(0.71)$ & $3.90(0.89)$ & $4.58(1.14)$ & $4.32(1.26)$ & 100 & $37.00(1.00)$ \\
5 & $99.41(0.53)$ & $4.87(0.77)$ & $5.58(0.91)$ & $4.28(0.88)$ & 100 & $37.00(1.00)$ \\
6 & $99.28(0.66)$ & $4.91(1.19)$ & $5.65(0.86)$ & $4.41(1.63)$ & 100 & $35.66(0.57)$ \\
7 & $99.17(0.51)$ & $4.94(0.88)$ & $5.73(0.62)$ & $4.87(0.97)$ & 100 & $37.00(1.00)$ \\
8 & $100.12(0.33)$ & $5.17(0.89)$ & $6.25(0.95)$ & $4.91(0.57)$ & 100 & $35.00(1.00)$ \\
9 & $99.81(0.39)$ & $5.26(0.89)$ & $6.96(0.95)$ & $5.08(1.08)$ & 100 & $36.33(1.00)$ \\
\hline
\end{tabular}

${ }^{a}$ Data shown are mean of three determinations and figure in the parentheses indicates standard deviation. 


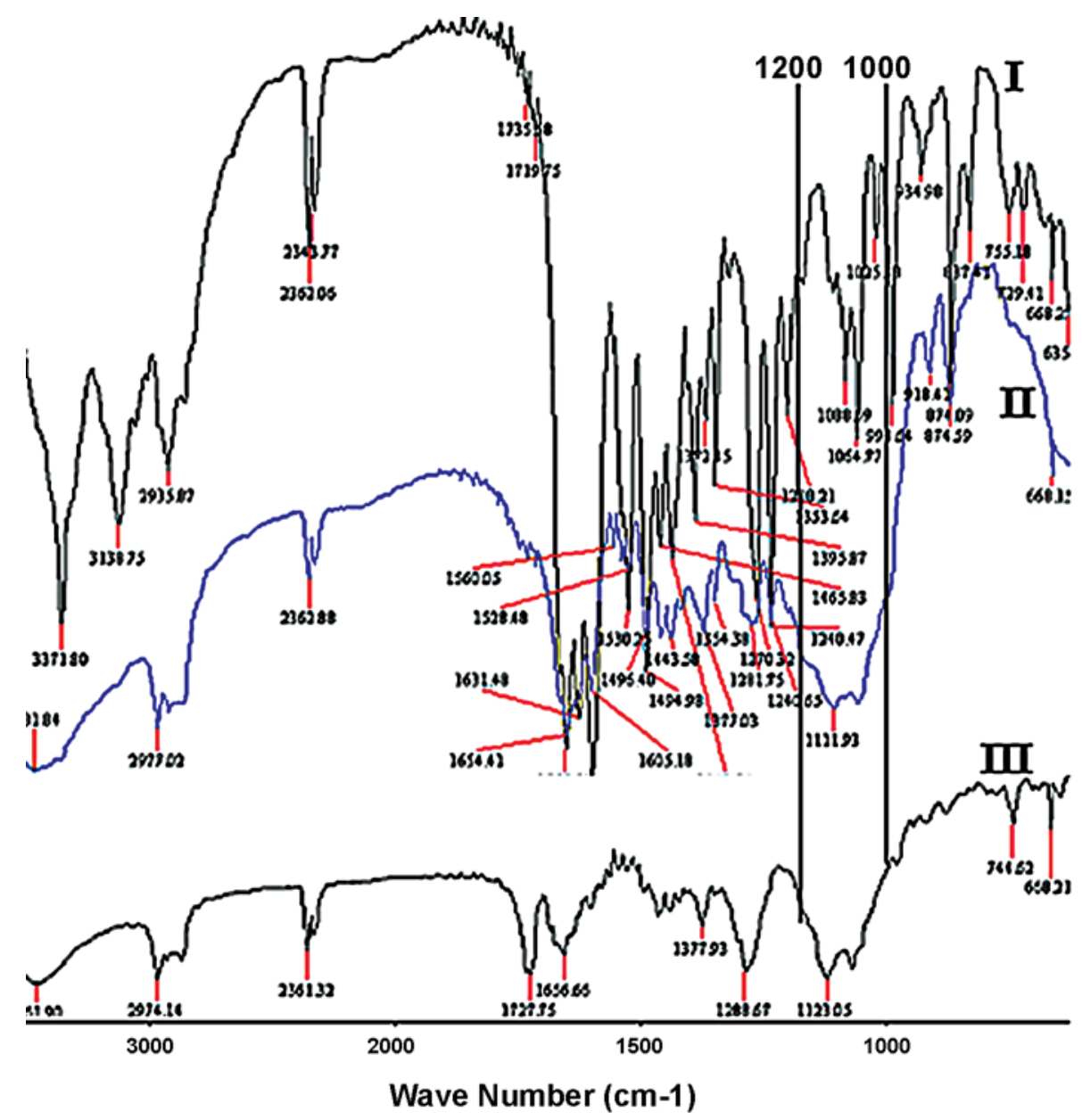

Figure 1 - FT IR spectra of alfuzosin hydrochloride (I); physical mixture of drug, ethyl cellulose and PVP (II) and transdermal film containing drug and polymers (III).

sion. Basically no change of frequency and shape of alfuzosin hydrochloride bands were observed, which suggests no significant redistribution of electronic density in the structure of organic molecule. This indicates no strong interaction between the drug and the polymers, in the film prepared by the solvent casting method.

\section{Scanning Electron Microscopy (SEM)}

The surface morphology of the formulation (run 9) was studied with SEM (Figure-2). Due to fairly good solubility of alfuzosin hydrochloride in the polymeric system, homogenously distributed drug particles were observed.

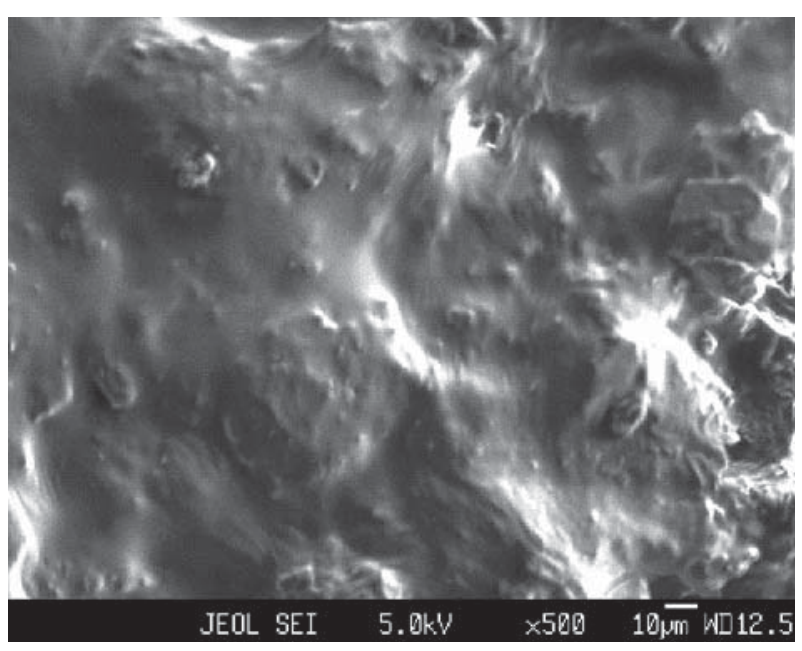

Figure 2 - Scanning electron micrographs of the transdermal film showing uniform distribution of drug in polymeric system. 
Table 3 - Model summary statistics.

\begin{tabular}{lcccccc}
\hline Source & \multicolumn{2}{c}{$\mathbf{Q}_{24}$} & & J & & P $_{\text {ss }}$ \\
& $\begin{array}{c}\text { Adjusted } \\
\text { R-Squared }\end{array}$ & PRESS & $\begin{array}{c}\text { Adjusted } \\
\text { R-Squared }\end{array}$ & PRESS & $\begin{array}{c}\text { Adjusted } \\
\text { R-Squared }\end{array}$ & PRESS \\
\hline Linear & 0.9258 & 412.49 & 0.9088 & 0.88 & 0.9315 & $2.103 \mathrm{E}-006$ \\
$2 \mathrm{FI}^{\mathrm{a}}$ & 0.9317 & 712.89 & 0.9086 & 1.74 & 0.9579 & $1.217 \mathrm{E}-006$ \\
Quadratic & 0.9695 & 504.67 & 0.9793 & 0.61 & 0.9836 & $1.487 \mathrm{E}-006$ \\
Cubic $^{\mathrm{b}}$ & 0.9939 & 860.85 & 0.9961 & 0.98 & 0.9970 & $2.343 \mathrm{E}-006$ \\
\hline
\end{tabular}

${ }^{a}$ two factor interaction; ${ }^{b}$ aliased model not to be selected; PRESS = predicted residual error sum of squares.

\section{In vitro Drug Permeation Studies}

Effects of the variables on the in vitro drug permeation from the transdermal films were studied by statistical experimental design. Experimental design has been widely used in pharmaceutical field to study the effect of formulation variables and their interactions on response variables $(10,15)$. In this study, a $3^{2}$ randomized full factorial design (Table-1) was used. A suitable equation involving the main effects was selected based on the estimation of several statistical parameters, such as the adjusted multiple correlation coefficient (adjusted $\mathrm{R}^{2}$ ) and the predicted residual error sum of squares (PRESS). As presented in Table-3, the quadratic model was selected as a suitable statistical model because it had the smallest value of PRESS and highest value of adjusted $\mathrm{R}^{2}$. Predicted residual error sum of squares (PRESS) is a measure of the fit of the model to the points in the design. The smaller the PRESS statistic is, the better the model fits to the data points (16). Cubic model has terms that are aliased and hence that model was not selected. Analysis of variance (ANOVA) was applied to estimate the significance of the model at the 5\% significance level. The quadratic model generated by the design is given below.

$\mathrm{Y}=\mathrm{b}_{0}+\mathrm{b}_{1} \mathrm{X}_{1}+\mathrm{b}_{2} \mathrm{X}_{2}+\mathrm{b}_{12} \mathrm{X}_{1} \mathrm{X}_{2}+\mathrm{b}_{11} \mathrm{X}_{1} \mathrm{X}_{1}+\mathrm{b}_{22} \mathrm{X}_{2} \mathrm{X}_{2}$

Where, $\mathrm{Y}$ is the dependent variable, $\mathrm{b}_{0}$ is the arithmetic mean response of the 9 runs, and $b_{i}\left(b_{1}, b_{2}\right.$, $\mathrm{b}_{12}, \mathrm{~b}_{11}$ and $\mathrm{b}_{22}$ ) is the estimated coefficient for the cor- responding factor $\mathrm{X}_{\mathrm{i}}\left(\mathrm{X}_{1}, \mathrm{X}_{2}, \mathrm{X}_{1} \mathrm{X}_{2}, \mathrm{X}_{1} \mathrm{X}_{1}\right.$ and $\left.\mathrm{X}_{2} \mathrm{X}_{2}\right)$, which represents the average result of changing one factor at a time from its low to high value. The interaction term $\left(\mathrm{X}_{1} \mathrm{X}_{2}\right)$ shows how the response changes when two factors are changed simultaneously. The polynomial terms $\left(\mathrm{X}_{1} \mathrm{X}_{1}, \mathrm{X}_{2} \mathrm{X}_{2}\right)$ are included to investigate nonlinearity. The final equations obtained in terms of coded factors as follows:

$\mathrm{Q}_{24}=+146.07+19.96 \mathrm{X}_{1}+7.61 \mathrm{X}_{2}-2.78 \mathrm{X}_{1} \mathrm{X}_{2}-5.38 \mathrm{X}_{1}^{2}-$ $0.29 \mathrm{X}_{2}^{2}$

$\mathrm{J}=+6.82+0.83 \mathrm{X}_{1}+0.32 \mathrm{X}_{2}-0.099 \mathrm{X}_{1} \mathrm{X}_{2}-0.28 \mathrm{X}_{1}^{2}$ $0.043 \mathrm{X}_{2}^{2}$

$\mathrm{Pss}=+0.006504+0.0008468 \mathrm{X}_{1}-0.001336 \mathrm{X}_{2}$ $0.000319 \mathrm{X}_{1} \mathrm{X}_{2}-0.0003011 \mathrm{X}_{1}^{2}+0.0002899 \mathrm{X}_{2}^{2}$

The permeation profile of all the experimental batches is shown in Figure-3. The coefficient estimate and standardized main effect (SME) values for the responses are listed in Table-4. SME values were calculated by dividing the main effects by the standard error of the main effects. In addition, the contour plots and three-dimensional response surface plots were presented to estimate the effects of the independent variables on each response. Results of multiple regression analysis and standardized main effects (SME) revealed that both ratio of EC: PVP (fraction of PVP) and drug loading had statistically significant influence on all dependent variables $(\mathrm{P}<$ 0.05 , Table-4).

The influence of ratio of EC: PVP and loading dose on $\mathrm{Q}_{24}$ is evident from the contour plot and 


\section{Alfuzosin Transdermal Films}

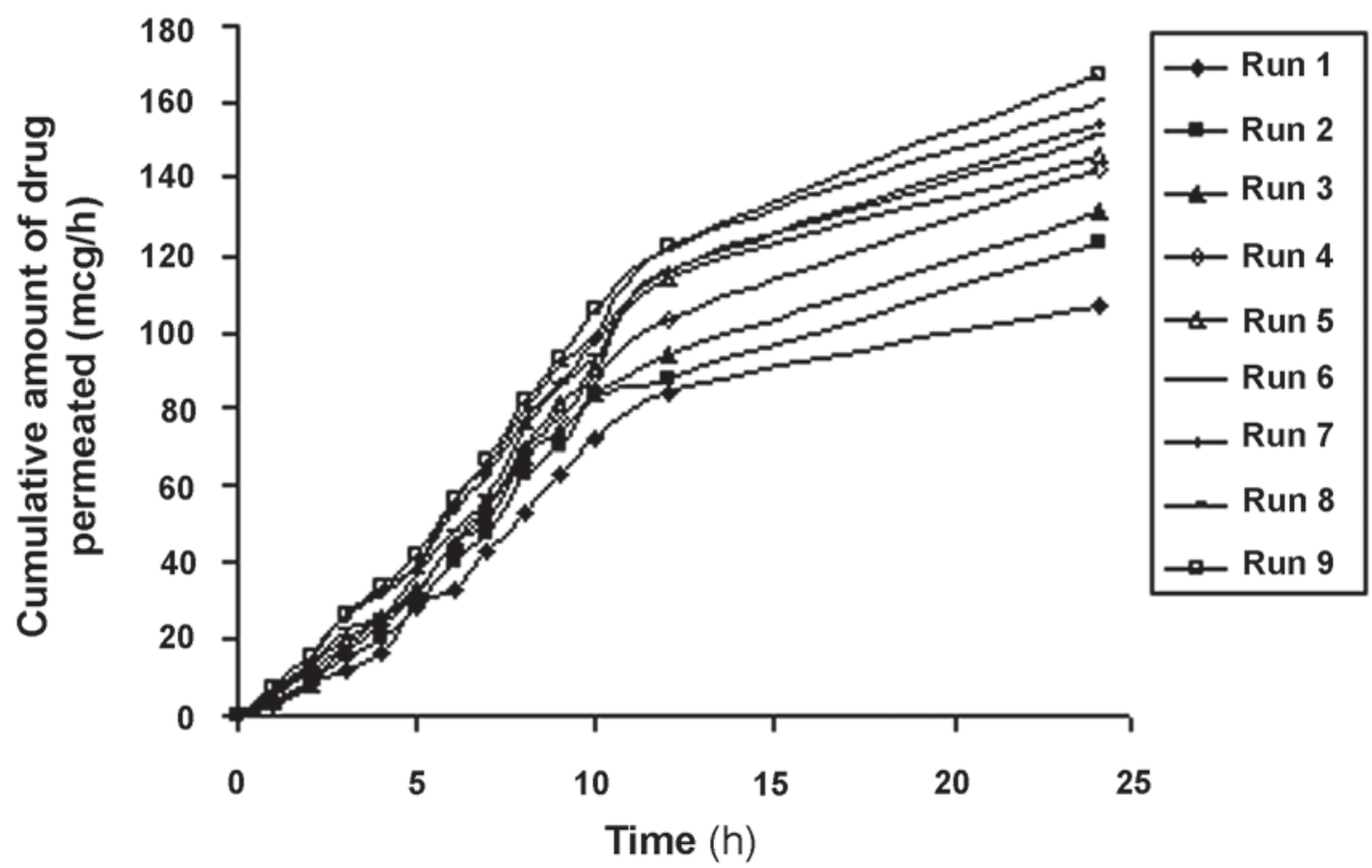

Figure 3 - In-vitro permeation profile of the factorial batches of alfuzosin hydrochloride transdermal films in normal saline as diffusion media.

Table 4 - Standardized main effects of the factors on the measured response parameters.

\begin{tabular}{lccccccccc}
\hline $\begin{array}{c}\text { Coefficient } \\
\text { of } \\
\begin{array}{c}\text { Regression } \\
\text { Parameter }\end{array}\end{array}$ & $\begin{array}{c}\text { Coefficient } \\
\text { Estimate }\end{array}$ & $\begin{array}{c}\mathbf{Q}_{24} \\
\text { Standard } \\
\text { Error }\end{array}$ & SME $^{\mathrm{a}}$ & $\begin{array}{c}\text { Coefficient } \\
\text { Estimate }\end{array}$ & $\begin{array}{c}\text { J } \\
\text { Standard } \\
\text { Error }\end{array}$ & SME $^{\mathrm{a}}$ & $\begin{array}{c}\text { Coefficient } \\
\text { Estimate }\end{array}$ & $\begin{array}{c}\mathbf{P}_{\text {Ss }} \\
\text { Standard } \\
\text { error }\end{array}$ & SME $^{\text {a }}$ \\
\hline $\mathrm{b}_{0}$ & 146.07 & 1.13 & 129.26 & 6.82 & 0.039 & 174.87 & 0.006504 & 0.00006133 & 106.05 \\
$\mathrm{~b}_{1}$ & 19.96 & 1.11 & 17.98 & 0.83 & 0.039 & 21.28 & 0.0008468 & 0.0000603 & 14.04 \\
$\mathrm{~b}_{2}$ & 7.61 & 1.11 & 6.85 & 0.32 & 0.039 & 8.20 & -0.001336 & 0.0000603 & -22.15 \\
$\mathrm{~b}_{12}$ & -2.78 & 1.36 & -2.04 & -0.099 & 0.047 & -2.10 & -0.000319 & 0.00007385 & -4.32 \\
$\mathrm{~b}_{11}$ & -5.38 & 1.64 & -3.28 & -0.28 & 0.057 & -4.91 & -0.003011 & 0.00008888 & -33.87 \\
$\mathrm{~b}_{22}$ & -0.29 & 1.64 & -0.17 & -0.043 & 0.057 & -0.75 & 0.0002899 & 0.00008888 & 3.26 \\
\hline
\end{tabular}

a Standardized main effects (SME) were calculated by dividing the main effect by the standard error of the main effect.

three-dimensional response surface plot (Figures-4 and 5). Regarding the overall effect of both factors, it was observed that $\mathrm{Q}_{24}$ was affected more by the levels of fraction of PVP, which was cleared from the response surface plot (Figure-5), as the decline of the $\mathrm{Q}_{24}$ value was more extreme on the axis of ratio 


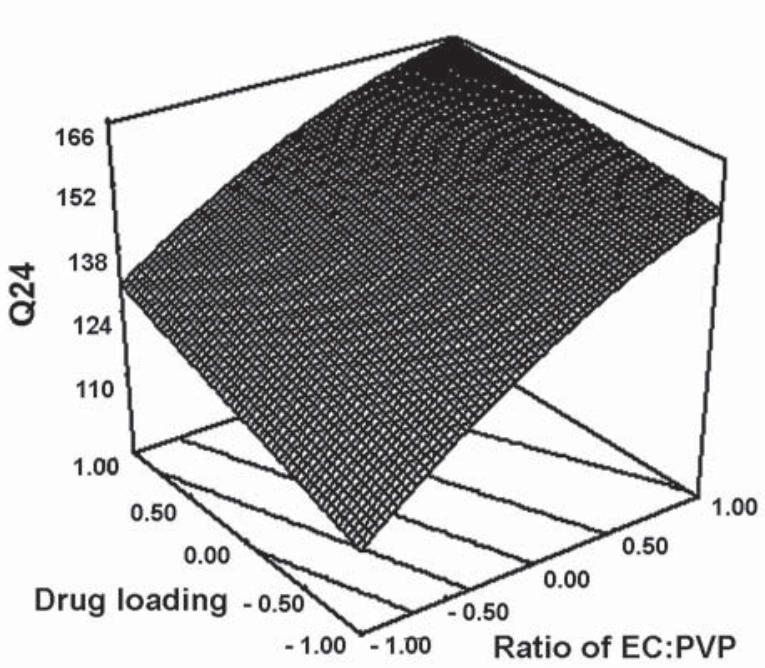

Figure 4-Contour plot for amount of drug permeated per $\mathrm{cm}^{2}$ of human cadaver skin at $24 \mathrm{~h}\left(Q_{24}\right)$ indicating the effect of the ratio of EC: $P V P$ and drug loading on $Q_{24}$

of EC: PVP compared with the drug loading. The higher SME value (17.98) of ratio of EC: PVP level indicated that the effect of ratio of EC: PVP level was found to be the main influential factor on the $Q_{24}$ from the transdermal films in the whole stage permeation. Less or negligible curvature on both axes in response surface plot indicates little contribution of interaction terms along with linearity of responses. It was found that the $\mathrm{Q}_{24}$ value increased with increase in fraction of PVP and drug loading. The addition of hydrophilic component to an insoluble film former (EC) tends to enhance the release rates, as reported by Arora et al. (13). The increase in the rate of drug release could be explained by the ability of the hydrophilic polymers to absorb water, thereby promoting the dissolution, and hence the release of drug. Moreover, the hydrophilic polymers would leach out and, hence, create more pores and channels for the drug to diffuse out of the films (17). It has also been reported that PVP decreases the crystallinity of the drug in film, which accounts for the increased release of the drug with an increase in the PVP concentration in the films (18).

It was also observed that the value of $\mathrm{Q}_{24}$ increased when drug loading was increased from $30 \%$ to $50 \%$. The increased release rate at high drug loading

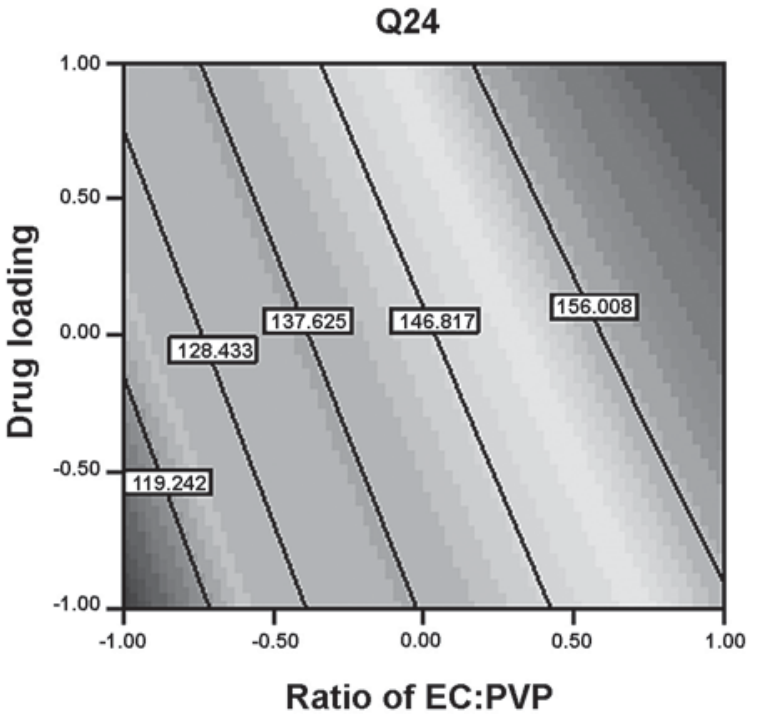

Figure 5 - Response surface plot for amount of drug permeated per $\mathrm{cm}^{2}$ of human cadaver skin at $24 \mathrm{~h}\left(Q_{24}\right)$ indicating the effect of the ratio of EC: $P V P$ and drug loading on $Q_{24}$.

might partly due to the drug entrapped in the superficial layer of the film. When the film comes in contact with diffusion medium, the drug from the surface leaches into the surrounding medium, leaving a more porous polymer structure, which enables faster drug diffusion from the matrix. Similar finding of metronidazole release from chitosan inserts has been reported by Barat et al. (19). Similar linearity of effect has also been reported by El-Arini et al. (20). One way ANOVA followed by Holm-Sidak test confirmed significant difference among the $\mathrm{Q}_{24}$ values of different runs.

Effect of Ratio of EC: PVP (fraction of PVP) and drug loading on $\mathrm{J}$ is evident from the contour plot and three-dimensional response surface plot (Figures-6 and 7). The larger SME value of ratio of EC: PVP level compared to SME value of drug loading indicated that the effect of ratio of EC: PVP level is the main influential factor on J. Steady state permeation flux was found to increase linearly when the independent variables were raised from lower level to higher level. A statistically significant difference was observed among all the runs, when subjected to one way ANOVA followed by Holm-Sidak test. A desired flux for alfuzosin hydrochloride from its transdermal system can be calculated from its pharmacokinetic pa- 


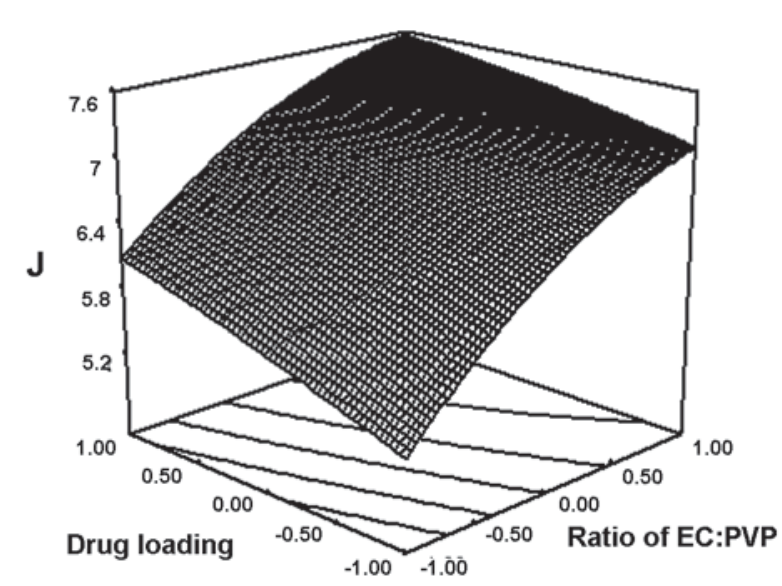

Figure 6 - Contour plot for permeation flux $(J)$ indicating the effect of the ratio of EC: PVP and drug loading on J.

rameters like required plasma concentration and total body clearance. The steady state plasma concentration data of alfuzosin hydrochloride is not available and in this event peak plasma concentration value, which is supposed to be within therapeutic window, may be considered as required plasma concentration for calculation of desired drug input rate. The mean peak plasma concentration $\left(\mathrm{C}_{\max }\right.$ ) of alfuzosin hydrochloride is $13.6 \mathrm{ng} / \mathrm{mL}$ and the total clearance $(\mathrm{Cl})$ is 0.3 $\mathrm{L} / \mathrm{h} / \mathrm{kg}$. Hence, the required rate of drug input can be calculated as follows:

Required rate of drug input $=$ Required plasma concentration $\times$ Clearance $=237.6 \mu \mathrm{g} / \mathrm{h}$.

Since, the maximum flux achieved with the experimental batch is $7.627( \pm 0.19) \mu \mathrm{g} / \mathrm{cm}^{2} / \mathrm{h}$, this indicates requirement of as large as $40 \mathrm{~cm}^{2}$ area film to achieve therapeutic plasma concentration. Though therapeutically effective amount of drug can be delivered by this delivery system, this type of large film should contribute towards patient non compliance and hence, permeation enhancers may be attempted in order to increase the flux and to decrease the required film size.

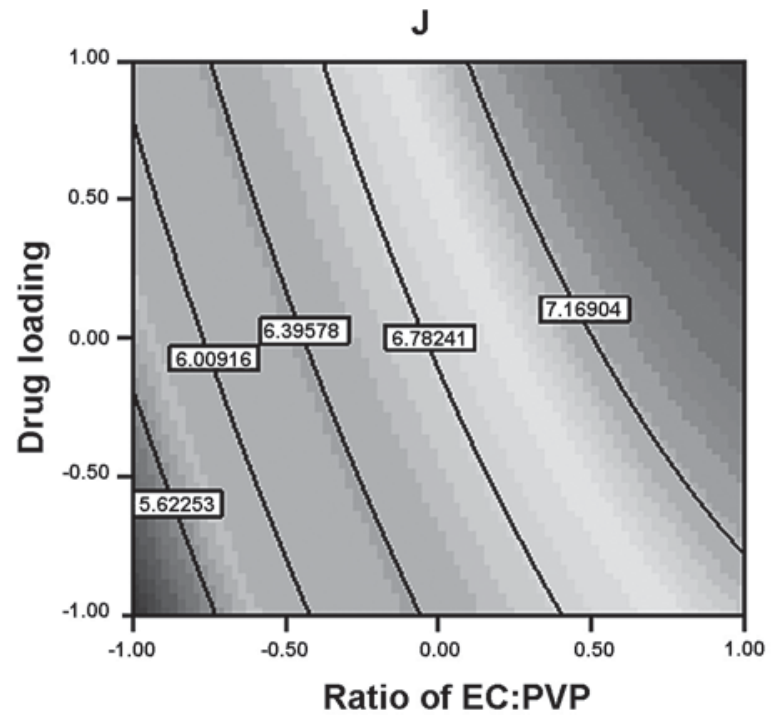

Figure 7-Response surface plot for permeation flux (J) indicating the effect of the ratio of EC: PVP and drug loading on J.

Figures- 8 and 9 are the response surface plot and contour plot respectively indicating influence of the independent variables on $\mathrm{P}_{\mathrm{SS}}$. It is cleared from the results of multiple regression analysis that the ratio of EC: PVP was the main influential factor on $\mathrm{P}_{\mathrm{sS}}$. A statistically significant difference was observed among all the runs when subjected to one way ANOVA followed by Holm-Sidak test.

The diffusion exponent values obtained after fitting the permeation data to peppas kinetic model found to range from 1.0632 to 1.291 indicating super case II transport as the mechanism of drug release from the matrix type transdermal systems.

\section{Activation Energy for Transdermal Permeability}

Good linearity $\left(\mathrm{R}^{2}=0.9935\right)$ observed in the Arrhenius plot indicate that Fick's law of diffusion is applicable to alfuzosin penetration through the skin, and the temperature dependent penetration is attributed to the passive diffusion. Activation energy (Ea) for permeation was estimated to be of $40.9 \mathrm{~kJ} /$ mol. 


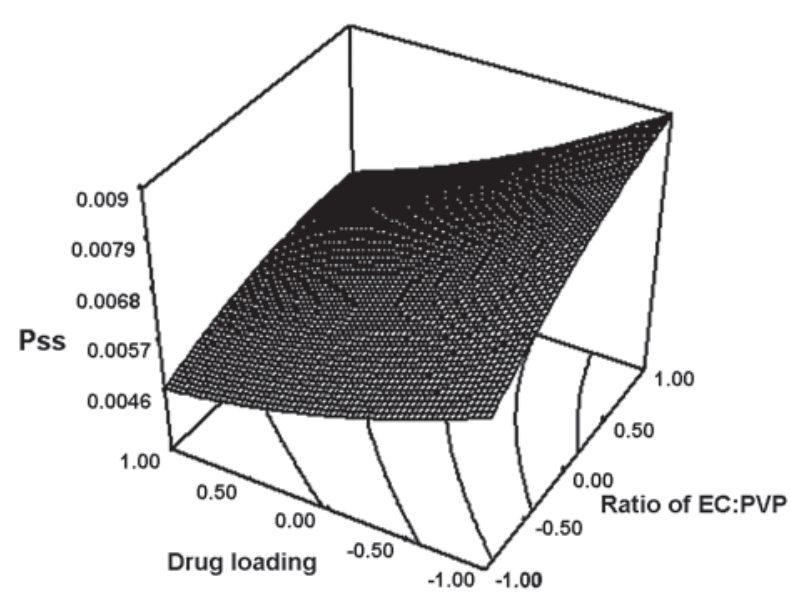

Figure 8-Contour plot for permeability coefficient $\left(P_{S S}\right)$ indicating the effect of the ratio of EC: PVP and drug loading on $P_{S S}$.

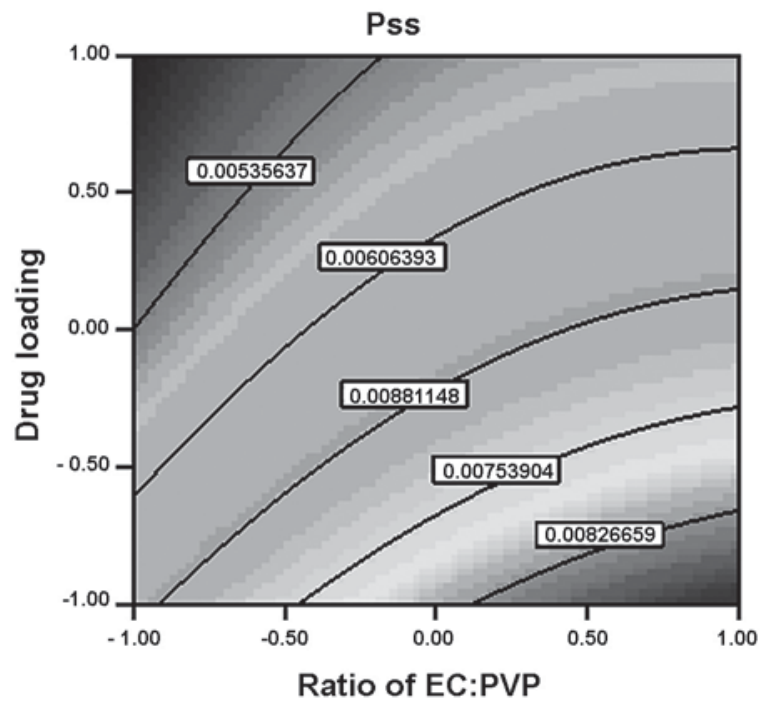

Figure 9 - Response surface plot for permeability coefficient $\left(P_{S S}\right)$ indicating the effect of the ratio of EC: PVP and drug loading on $P_{S S}$

Table 5 - Primary skin irritation study results.

\begin{tabular}{lcccc}
\hline Animal N. & \multicolumn{3}{c}{ Erythema/Edema Scores after Hours of Film Removal } \\
& 1 & 24 & 48 & 72 \\
\hline 01 & $0 / 0$ & $0 / 0$ & $0 / 0$ & $0 / 0$ \\
02 & $0 / 0$ & $0 / 0$ & $0 / 0$ & $0 / 0$ \\
03 & $1 / 0$ & $1 / 0$ & $0 / 0$ & $0 / 0$ \\
04 & $0 / 0$ & $0 / 0$ & $0 / 0$ & $0 / 0$ \\
05 & $1 / 0$ & $0 / 0$ & $0 / 0$ & $0 / 0$ \\
06 & $0 / 0$ & $0 / 0$ & $0 / 0$ & $0 / 0$ \\
Total & $2 / 0$ & $1 / 0$ & $0 / 0$ & $0 / 0$ \\
Mean & $0.33 / 0.00$ & $0.16 / 0.00$ & $0.00 / 0.00$ & $0.00 / 0.00$ \\
PDI $^{\mathrm{b}}$ & 0.33 & 0.16 & 0.00 & 0.00 \\
PDII $^{\mathrm{c}}$ & & & & \\
\hline
\end{tabular}

${ }^{a}$ A five point scale was used for scoring as follows: no erythema/edema- 0/0, very slight - 1/1, slight-2/2, moderate - 3/3, severe- 4/4. ${ }^{b}$ Primary dermal irritation (PDI) score is obtained by adding average erythema and average edema scores. ${ }^{c}$ Primary dermal irritation index (PDII) is obtained by adding the PDI scores for 1, 24, 48 and 72 hour scoring intervals and dividing by the number of scoring intervals.

\section{Primary Skin Irritation Studies}

Primary skin irritation study should be performed for all dosage forms, which are applied onto the skin to exclude any possibility of potential dermal irritation. A primary dermal irritation index (PDII) of 0.12 (Table-5) for the test transdermal film indicated that the film is non irritating and safe for dermal application. 


\section{Alfuzosin Transdermal Films}

\section{Stability Studies}

The results of the short term stability studies are encouraging with less than $0.5 \%$ variation in drug content. The physical appearance of the test film was found unchanged indicating a stable formulation.

\section{CONCLUSION}

The physicochemical evaluation indicated that the developed transdermal delivery systems of alfuzosin hydrochloride are technologically satisfactory. Both the independent variables were found to influence the measured in vitro human cadaver skin permeation responses. Although therapeutically effective amount of drug can be delivered by this delivery system, permeation enhancement strategies need to be adopted to decrease the film size, which will contribute towards patient compliance. The prepared formulations were found to be dermatologically non irritant.

\section{CONFLICT OF INTEREST}

None declared.

\section{REFERENCES}

1. Garraway WM, Collins GN, Lee RJ: High prevalence of benign prostatic hypertrophy in the community. Lancet. 1991; 338: 469-71.

2. Rossi C, Kortmann BB, Sonke GS, Floratos DL, Kiemeney LA, Wijkstra H, et al.: alpha-Blockade improves symptoms suggestive of bladder outlet obstruction but fails to relieve it. J Urol. 2001; 165: 38-41.

3. Djavan B, Marberger M: A meta-analysis on the efficacy and tolerability of alpha1-adrenoceptor antagonists in patients with lower urinary tract symptoms suggestive of benign prostatic obstruction. Eur Urol. 1999; 36: 1-13.

4. McKeage K, Plosker GL: Alfuzosin: a review of the therapeutic use of the prolonged-release formulation given once daily in the management of benign prostatic hyperplasia. Drugs. 2002; 62: 633-53.
5. Roehrborn CG: Alfuzosin: overview of pharmacokinetics, safety, and efficacy of a clinically uroselective alpha-blocker. Urology. 2001; 58 (6 Suppl 1): 55-63; discussion 63-4.

6. Liu Q, Fassihi R: Zero-order delivery of a highly soluble, low dose drug alfuzosin hydrochloride via gastro-retentive system. Int J Pharm. 2008; 348: 27-34.

7. Barry BW: Breaching the skin's barrier to drugs. Nat Biotechnol. 2004; 22: 165-7.

8. Ramírez-Campos M, Villafuerte-Roble L: Effect of Formulation Variables on Verapamil Hydrochloride Release from Hydrated HPMC Matrices. Rev Soc Quím Méx. 2004; 48: 326-31.

9. Arora P, Mukherjee B: Design, development, physicochemical, and in vitro and in vivo evaluation of transdermal patches containing diclofenac diethylammonium salt. J Pharm Sci. 2002; 91: 2076-89.

10. Swain K, Pattnaik S, Mallick S, Chowdary KA: Influence of hydroxypropyl methylcellulose on drug release pattern of a gastroretentive floating drug delivery system using a 3(2) full factorial design. Pharm Dev Technol. 2009; 14: 193-8.

11. Grass GM, Robinson JR: Mechanisms of corneal drug penetration. I: In vivo and in vitro kinetics. J Pharm Sci. 1988; 77: 3-14.

12. Kawazu K, Midori Y, Shiono H, Ota A: Characterization of the carrier-mediated transport of levofloxacin, a fluoroquinolone antimicrobial agent, in rabbit cornea. J Pharm Pharmacol. 1999; 51: 797-801.

13. Draize JH, Woodard G, Calvery HO: Methods for the study of irritation and toxicity of substances applied topically to the skin and mucous membranes. J Pharmacol Exp Ther. 1944; 82: 377-90.

14. Arora P, Mukherjee B: Design, development, physicochemical, and in vitro and in vivo evaluation of transdermal patches containing diclofenac diethylammonium salt. J Pharm Sci. 2002; 91: 2076-89.

15. Pattnaik S, Swain K, Mallick S: Influence of polymeric system and loading dose on drug release from alfuzosin hydrochloride transdermal films. Lat. Am. J. Pharm. 2009; 28: 62-9.

16. Segurola J, Allen NS, Edge M, McMahon A: Design of eutectic photoinitiator blends for UV/visible curable acrylated printing inks and coatings. Prog Org Coat. 1999; 37: 23-37.

17. Bodmeier R, Paeratakul O: Evaluation of drug-containing polymer films prepared from aqueous latexes. Pharm Res. 1989; 6: 725-30.

18. Guyot M, Fawaz F: Design and in vitro evaluation of adhesive matrix for transdermal delivery of propranolol. Int J Pharm. 2000; 204: 171-82. 


\section{Alfuzosin Transdermal Films}

19. Barat R, Srinatha A, Pandit JK, Anupurba S, Mittal N: Chitosan inserts for periodontitis: influence of drug loading, plasticizer and crosslinking on in vitro metronidazole release. Acta Pharm. 2007; 57: 469-77.
20. Bhardwaj SB, Shukla AJ, Collins CC: Effect of varying drug loading on particle size distribution and drug release kinetics of verapamil hydrochloride microspheres prepared with cellulose esters. J Microencapsul. 1995; 12: $71-81$.

\section{Correspondence address:}

Dr. Satyanarayan Pattnaik

Percutaneous Drug Delivery Systems

Department of Pharmaceutics

College of Pharmaceutical Sciences

Mohuda, Berhampur, 760002, Orissa, India

Fax: + 9106802261752.

E-mail: saty3000@yahoo.com 